expense of non-conceptive strategies that animals might be pursuing. I could not agree more. But there is a Rip Van Winkle quality to all this.

Far from being "just realized", these problems were discussed in the 1970s and 1980 s by female sociobiologists, who called for a broadening of evolutionary theories to include selection pressures at more levels and on a broader range of individuals (such as females and juveniles). Roughgarden mentions some of these critiques in passing, but without exploring the impact that such findings are already having. Even though the push for revisions began on the margins of evolutionary theorizing, change (however inefficiently reached) came from within. This process is representative of how science works. Over the long haul, researchers (especially young ones) have less to gain from suppressing information about diversity than from making their reputations by exploring it

Yes, it took a long time. But once the previously marginalized (Katherine Ralls, Mary Jane West-Eberhard, Patricia Adair Gowaty, Barbara Smuts and myself, to name only a few) had gained enough influence to be heard, evolutionary horizons began to broaden. Far from trying to suppress our

\section{High points in geology}

Devil in the Mountain: A Search for the Origin of the Andes

by Simon Lamb

Princeton University Press: 2004. 336 pp.

$\$ 29.95, £ 19.95$

\section{David E. James}

Devil in the Mountain is the fascinating story of geologist Simon Lamb's quest to understand how the high Andes formed. It includes a wealth of real-life, even harrowing, anecdotes of fieldwork, mixed with colourful descriptions of Bolivian culture. This engrossing and well-written book focuses on deciphering how the modern Andes, and high mountains in general, took shape on the surface of the Earth. Lamb parses the Andean story for us, piece by piece, as he came to understand the process. The reader travels with him by Toyota Land Cruiser through the Bolivian Andes as he sorts through the clues to their growth. We share with him his experiences in New Zealand and Scotland, his opportune conversations with fellow scientists, and a host of other disparate threads that became the building blocks of his understanding of how high mountains are formed.

The story unfolds in the central Andes, the highest and widest part of the Andean chain that runs the length of western South views, new generations of sociobiologists rushed past us to explore the expanding frontiers. Theories that were never so much false as incomplete and overextended are already beginning to be revised. Roughgarden's book will similarly galvanize research in the transsexual realm of the great continuum of diversity out there.

But I fear that her book may also mislead readers on two counts. First, competition between those of one sex for reproductive access to the other remains a robust explanatory framework, even though it is not the whole story. Second, I fear that Roughgarden's "indictment" will fuel widespread misunderstandings about the way in which scientists operate.

Unquestionably, many medical professionals were slow to understand what being transgendered means. Lives were sacrificed to dogmatic surgical and psychological interventions. Some hopelessly unreflective scientists continue to "sneak gender stereotypes into the primary scientific literature and corrupt its objectivity", aided and abetted by sloppy popularizers. Raising the consciousness of darwinists is taking longer than ideally it might have. Nor have evolutionary biologists always been candid in acknowledging either the sources of our biases or how such biases came to be corrected. Evolutionary biology does indeed have its share of die-hard dogmatists.

But the biases that Roughgarden highlights have less to do with false theories or cover-ups than with the occupational hazards of being human, of tending to see what we expect (or sometimes want) to see and incorporating prejudiced observations into our starting assumptions. Empathy (just whose interests we identify with) plays a much greater role in the biological and social sciences than is generally acknowledged. It is even possible that learning biases are built into human psychology, preventing us from noticing things counter to our own (including our gender's) interests. But these are not reasons to reject sexual-selection theory; they are merely reasons to encourage diversity among those applying it, the better to study nature's rainbows, sexual and otherwise. Hopefully, Roughgarden's book will be one more step towards that goal.

Sarah Blaffer Hrdy is professor emeritus in the Department of Anthropology, University of California, Davis, California 95616, USA. Her most recent book is Mother Nature: A History of Mothers, Infants, and Natural Selection.

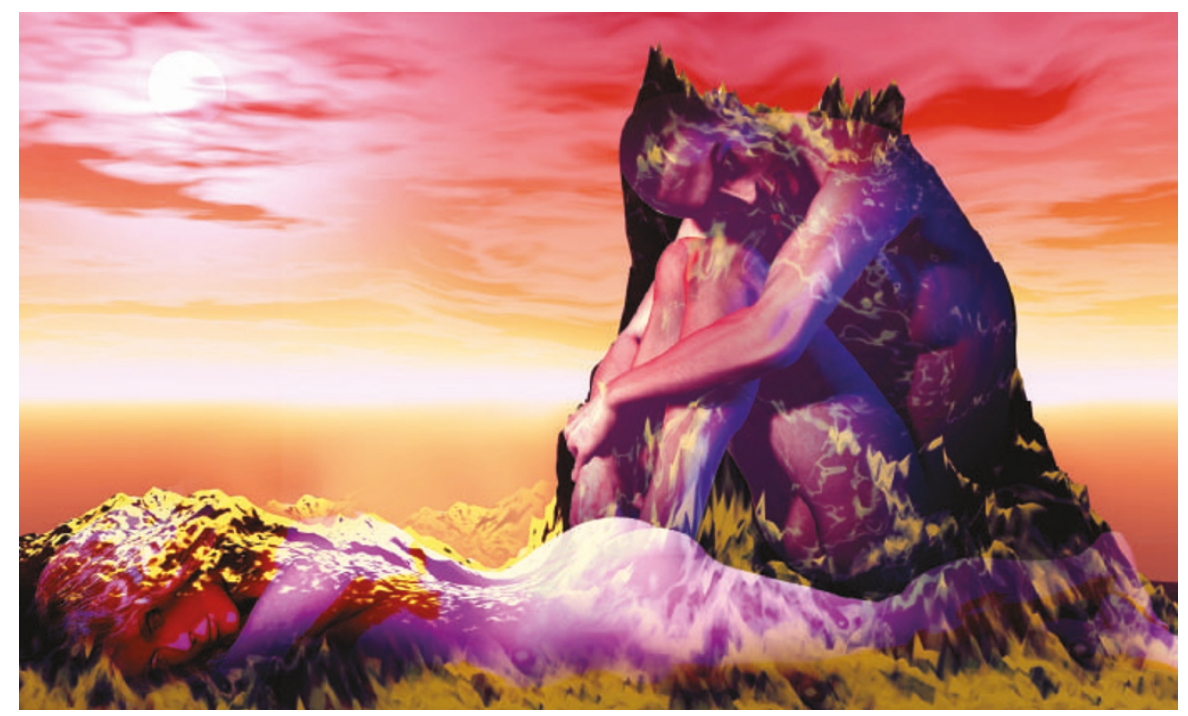

America. Here the great volcanic peaks of the Western Cordillera and the tectonically folded and faulted ranges of the high Eastern Cordillera are split from one another by one of the world's greatest plateaux, the altiplano, situated an imposing 4,000 metres above sea level. Lamb staked out his territory in 1989 in the Eastern Cordillera of Bolivia, and he and his students embarked on a protracted study to understand what drove the Andes to such great heights.

Lamb begins by explaining how he came to study the Andes in the first place, and the origins of the book's title - a reference to the evil underground spirits that Bolivian miners believe decide the fate of each mine, and which they appease with a statue and offerings at the mine entrance. Then we divert to northern Scotland where Lamb introduces the enigma not just of mountain building but of Earth's evolution itself, starting with the early scientific breakthroughs that revealed deep geologic time and thence along the tortuous path of scientific ideas to the dawn of plate tectonics. The narrative of Lamb's own journey of discovery is inextricably linked to plate tectonics, which lies at the heart of all understanding of the Andes.

Lamb's writing is engaging and clear, making for a thoroughly accessible book. He is at his best showing how geologists decipher the clues hidden in outcrops and the 
landscape. Even when he tackles esoteric areas of geophysics and dynamical modelling far from his own field of expertise, Lamb exhibits an enviable facility for simplifying complex and, in some cases, quite controversial ideas. He has keen insight into Bolivian geology and a sympathetic eye for local culture. His description of his first visit to La Paz was eerily reminiscent of my own experience some 20 years earlier - from the outof-breath climb to the seismic Observatorio San Calixto and the indispensable meeting with its director, Father Cabré, to the struggles over drafting a formal agreement, or convenio, with the Bolivian Geological Survey.

Amid all the hazards and exhilaration of fieldwork in a distant land, Lamb succeeds in capturing Bolivia: the pervasive smell of diesel fumes mixed with an aroma of urine in the streets of $\mathrm{La} \mathrm{Paz}$; the "thirty-six signatures, several from the same official" required to get equipment through customs; the endless efforts to keep dilapidated vehicles running on atrocious roads at high altitude; the bewildering networks of rutted tracks in the altiplano that go nowhere; the omnipresent military checkpoints; and the almost unbelievably hard life of the average Bolivian miner or campesino.

As a popular account of Andean formation, Devil in the Mountain makes compelling reading. Lamb has done a masterful job in piecing together the Andean puzzle in a way that seems to make perfect sense. Nonetheless, from a strictly scientific point of view, his highly personalized take on the origins of the Andes contains numerous controversial ideas, and the scientific community remains split on many key questions. Lamb reveals throughout a strong Oxbridgecentrism (he is, after all, an Oxford lecturer with a $\mathrm{PhD}$ from Cambridge) that dominates many of the 'big picture' sections in the later chapters. Moreover, the same big picture that makes sense in one part of the Andes may not do so in another. To his credit, he is well aware of the unfortunate way in which research into the Andes has been compartmentalized over the years, and has worked harder than most to escape the provincial thinking that comes with it.

Only occasionally does he stumble outright, for example when he seemed unaware in 1995 that seismic and gravity studies had shown 25 years previously that a deep root beneath the Andes compensated for the high elevations. Overall, however, these few reservations seem to be relatively minor grains of salt to swallow. Despite many personal quibbles of my own, I thoroughly enjoyed this book, which in the end is a fair and plausible account of how high mountains are born and how they die — and even, perhaps, how they affect the life of the planet.

David E. James, is in the Department of Terrestrial Magnetism, Carnegie Institution of Washington, Washington DC 20015, USA.

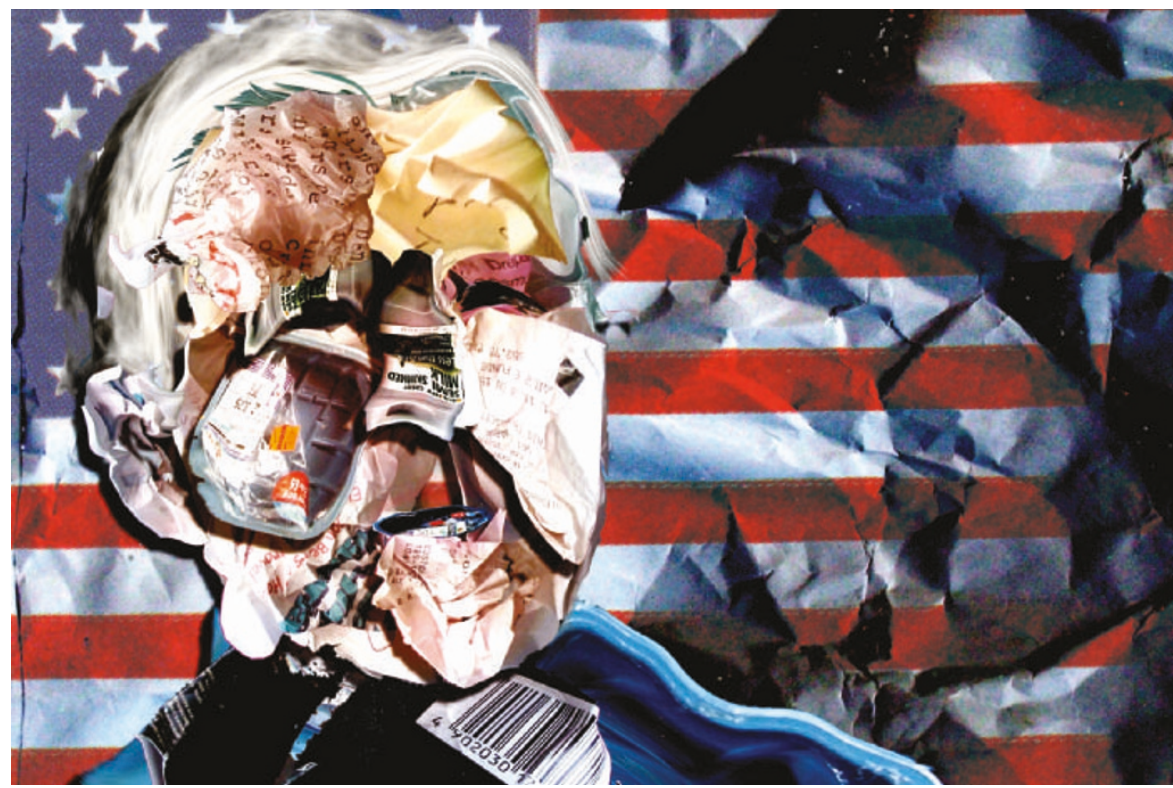

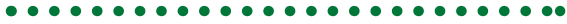

\section{The way or the world}

\section{One with Nineveh: Politics, Consumption and the Human \\ Future}

by Paul R. Ehrlich \& Anne H. Ehrlich Island Press: 2004.430 pp. \$27

\section{Norman Myers}

What, you might say, yet another book from Paul and Anne Ehrlich on the environment, population and consumption, and about how humans are grossly degrading Earth's life-support systems? Can the Ehrlichs have anything new and different to offer about the crises they have been trumpeting for decades? Well, they certainly do in this latest book, which is full of pioneering analyses and innovative insights.

The book's initial purpose is to present our predicament in terms of the environmental ruin, fostered by political hubris and citizens' myopia, that overtook the ancient Assyrian capital Nineveh. The disaster was poetically exemplified by Rudyard Kipling's "Lo, all our pomp of yesterday/Is one with Nineveh and Tyre."

After this stage-setting, the Ehrlichs review our dire environmental prospect, focusing on shortages of food and energy, biodepletion, loss of ecosystem services, and grand-scale pollution, among a litany of related ills. Then they assert that there are two principal drivers of our predicament: too many people and too much consumption. All these topics are dealt with in detail and with evidence piled on evidence. Certain sections could have been compressed, as they have been rehearsed on many occasions already - even if not everyone has been listening.

Parts of the book are a vigorous critique of US President George W. Bush and his policies - and, by extension, of the ultra-right community that seems to dominate American society. Bush often reiterates his father's thesis, as enunciated, for example, at the Rio Earth Summit in 1992 when Bush senior declared, with reference to his country's fixation on fossil fuels: "The American way of life is not negotiable." Both presidents Bush have asserted that a shift away from fossil fuels would knock deep dents in the US economy. And both have failed to see that it is precisely the fixation on fossil fuels that will, courtesy of global warming, transform the American way of life from top to bottom. I suspect that people of the future will not regard today's spot price of oil or the latest sales figures for sports utility vehicles as the key statistics of our time, rather that the United States, with $4.6 \%$ of the world's population, produces $24 \%$ of the world's carbon dioxide emissions.

The Ehrlichs deal several times with the absurdity, if not the arrogance, of the presidential proclamations, pointing out that not even the United States, however powerful it may be, can insulate itself from links with the climate. The winds carry no passports and Americans are becoming, first and foremost, citizens of the global community, even though many of them prefer to proclaim their 'exceptionalism'. They epitomize the dictum that, first, no country can support an indefinite increase either in its number of people or in its consumption of environmental resources, let alone both; and second, most mainstream policies of most governments assume, on the contrary, that they can. This is true of most nations, to a degree, but the United States is in a league of its own.

The environmental crisis has been well covered in the Ehrlichs' earlier books, so what is new and different about this one? Here the Ehrlichs offer us much more on the hard-nosed solutions needed to expand 